\title{
Aquatic invasive species: introduction to the Special Issue and dynamics of public interest
}

\author{
Katya E. Kovalenko $\mathbb{D} \cdot$ Fernando M. Pelicice $\cdot$ Lee B. Kats $\cdot$ Jonne Kotta \\ Sidinei M. Thomaz
}

Received: 3 March 2021 / Revised: 31 March 2021/Accepted: 3 April 2021 / Published online: 22 April 2021

(C) The Author(s), under exclusive licence to Springer Nature Switzerland AG 2021

\begin{abstract}
Aquatic invasive species research has been surging in popularity, with the number of papers published in Hydrobiologia doubling since the previous decade. We overview contributions to the current Special Issue, including new studies on introduction and establishment, traits distinguishing high-impact invaders and their impacts, interactions between AIS and other human stressors as well as new developments in management. In addition, we analyze public interest in invasive species using 17 years of data (2004-2020) on absolute search volumes from Google extracted using Keywords Everywhere app. In particular, we analyze trends in searches for invasive species in general, several high-impact AIS, as well as the popularity of invasive species searches contrasted with
\end{abstract}

Guest editors: Katya E. Kovalenko, Fernando M. Pelicice, Lee B. Kats, Jonne Kotta \& Sidinei M. Thomaz / Aquatic Invasive Species III.

K. E. Kovalenko $(\bowtie)$

Natural Resources Research Institute, University of Minnesota, Duluth, 5013 Miller Trunk Highway, Duluth, MN, USA

e-mail: ekovalen@d.umn.edu

F. M. Pelicice

Núcleo de Estudos Ambientais, Universidade Federal de Tocantins, Rua 3, Quadra 17, Jardim dos Ipês,

Porto Nacional, Tocantins 77500-000, Brazil

L. B. Kats

Natural Science Division, Pepperdine University, Malibu, CA 90263, USA other commonly recognized ecological problems in aquatic ecosystems. During the available search period, search volume for invasive species in general has increased and compared favorably with other ecological issues, whereas search volume patterns for high-impact AIS were species-specific and often exceeded search volumes for the general keyword. Public engagement is critical for all aspects of AIS research and management, and analysis of search volumes can be used to gauge, sustain and diversify this engagement.

Keywords Google Trends · Keywords Everywhere · Non-native species $\cdot$ Search volume $\cdot$ Culturomics . Public opinion
J. Kotta

Estonian Marine Institute, University of Tartu, Mäealuse 14, Tallinn 12618, Estonia

S. M. Thomaz

Universidade Estadual de Maringá, DBI/PEA/Nupélia, Av. Colombo 5790, Maringá, PR 87020-900, Brazil 


\section{Introduction}

As mostly inadvertent large-scale experiments, invasive species (i.e., established and spreading non-native species, e.g., Havel et al., 2015) have boosted many fields of ecological research (e.g., Sax et al., 2005). Invasive species have also defied many elegant ecological theories (Boltovskoy et al., 2021), underscoring the limited power of the reductionistic approach to complex ecological systems and the limited success of generalization of patterns across habitats and species. If a single novel species can trigger such extreme community re-organization and loss of ecosystem services on landscape scales (e.g., Ehrenfeld, 2010; Gallardo et al., 2016), what does this tell us about functional extinction of multiple species, all the disappearing threads in ecological networks?

Several recent reviews provide a good starting point to explore various aspects of aquatic invasive species (AIS) research including impacts modeling (GuyHaim et al., 2018; Anton et al., 2019; Corrales et al., 2020; Thomsen 2020), traits and impacts (Boltovskoy et al., 2021), invasion syndromes (Novoa et al., 2020), first record rates (Seebens et al., 2017), effects on endangered and threatened species (Dueñas et al., 2018), food web effects (Gallardo et al., 2016; David et al., 2017), role of parsites in marine invasions (Goedknegt et al., 2016), impacts on ecosystem functions and services (Flood et al., 2020), management and eradiation (Simberloff, 2021), social perception (Kapitza et al., 2019) and policy issues (Geller et al., 2020).

AIS have also contributed to a greater awareness of cultural ecosystem services as we lament our visibly changed lakes and rivers, and with them the loss of meaningful connections to the landscape. AIS hold a special place in the public psyche, enjoying a high level of problem recognition, that is often reflected in decisiveness to act and the distribution of research and management funding (e.g., Tyner \& Boyer, 2020), in comparison to some other issues plaguing aquatic ecosystems and likely causing a greater proportion of extinctions (Dueñas et al., 2018) worldwide such as habitat modification and destruction (Pelicice et al., 2017; Guy-Haim et al., 2018; Dudgeon, 2019; Van Riper et al., 2019). The many possible reasons for this AIS spotlight include capacity to cause rapid and conspicuous changes on large scales; being a nonhuman driver of destruction; being a well-defined, actionable threat, sometimes with a possibility for commercial solutions; being a local problem; xenophobia; substantial economic impacts of high-impact invaders as well as the strong emphasis on negative effects resulting from a limited focus on those highimpact invaders (Anton et al., 2019) and the resulting social media attention. These reasons are often nonindependent and difficult to disentangle, and there is limited understanding of their relative importance. But AIS have undoubtedly contributed to increasing awareness of the vulnerability of aquatic habitats, both freshwater and marine, and exploring the connection between public perception of AIS and successful management and control of AIS is a promising area of research (Lennox et al., 2015; Giakoumi et al., 2019). In this preface, we overview the contributions to the current Special Issue and analyze internet search volume trends (using Keywords Everywhere app with Google Chrome) to gauge public interest in invasive species in general, specific high-impact AIS, and the relative interest in invasive species compared to other environmental issues in aquatic ecosystems.

\section{Overview of the current Special Issue}

Invasive species research is becoming increasingly important in both aquatic and general ecology journals (Thomaz et al., 2015). The percentage of invasive species-related papers to all papers published in Hydrobiologia has doubled from the previous assessment: it has reached $22.2 \%$ of all papers $(\mathrm{N}=1280)$ published in $2018-2020$, vs. $10.7 \%$ of all papers published in 2008-2017 (Havel et al., 2018). Similar to the previous two Special Issues of Hydrobiologia on AIS (Thomaz et al., 2015, Havel et al., 2018), this issue covers a wide range of habitats, organisms and topics (Table 1).

Introduction and establishment

Effective AIS prevention relies on accurate identification of major introduction pathways and their timely and successful regulation. Aquaculture and the aquarium trade have long been recognized as one of the main pathways for AIS introductions (Magalhães et al., 2020). In this issue, Forneck et al. (2021) demonstrate that aquaculture intensity is a good predictor of catch frequency of a known high-impact 
Table 1 Topics, organisms, and aquatic ecosystems studied in the 29 papers included in this special issue of Hydrobiologia

\begin{tabular}{|c|c|c|c|}
\hline Topic & Organism & Ecosystem/Experiment & Authors \\
\hline \multicolumn{4}{|l|}{ Introduction and establishment } \\
\hline Aquaculture as an introduction pathway & Freshwater fish & Streams & Forneck et al., \\
\hline Online marketplaces as a pathway for invasions & All taxa & Freshwater & Olden et al., \\
\hline Regional translocation of non-native species & $\begin{array}{l}\text { Invertebrates (multiple } \\
\text { taxa) }\end{array}$ & $\begin{array}{l}\text { Marine (Southeast } \\
\text { Atlantic) }\end{array}$ & Meloni et al., \\
\hline Risk screening of the potential invasiveness & $\begin{array}{l}\text { Crustaceans and } \\
\text { barnacles }\end{array}$ & Marine (Mediterranean) & Stasolla et al., \\
\hline Tally, policy, and outlook for AIS & $\begin{array}{l}\text { Multiple multicellular } \\
\text { taxa }\end{array}$ & Marine (Mediterranean) & Galil et al., \\
\hline $\begin{array}{l}\text { Establishment as a function of phylogenetic } \\
\text { distance }\end{array}$ & Fish & Lakes & $\begin{array}{l}\text { Rocha \& } \\
\text { Cianciaruso }\end{array}$ \\
\hline Role of habitat connectivity & Freshwater bivalve & Floodplain & de Amo et al., \\
\hline Latitudinal gradients in AIS & All taxa & Freshwater/marine & Santos et al., (a) \\
\hline \multicolumn{4}{|l|}{ What distinguishes high-impact AIS? } \\
\hline Plant thermal plasticity & Macrophytes & Microcosm & Thiébaut et al., \\
\hline Geographic distribution and use of substrate & Echinodermata & Marine & Tavares et al., \\
\hline Increasing climatic range during invasion & Dinoflagellate & Freshwater & Macêdo et al., \\
\hline Traits contributing to invasiveness & Macrophytes & Freshwater & Hussner et al., \\
\hline Environmental and seasonal responses of an AIS & Freshwater snail & Lakes and streams & Verhaegen et al., \\
\hline Parasite loads and diversity of AIS & Fish & Rivers and reservoirs & Ondračková et al., \\
\hline Effect of an invasive on a native congener fish & Fish & Floodplain & Ganassin et al., \\
\hline Predatory impact of an invasive fish & Fish & Mesocosm & Carvalho et al., \\
\hline Influence of parasitism on fitness & Freshwater bivalve & Microcosm & Liquin et al., \\
\hline \multicolumn{4}{|l|}{ Impacts of invaders } \\
\hline Traits and impacts of non-native species & All taxa & $\begin{array}{l}\text { Freshwater/marine/ } \\
\text { terrestrial }\end{array}$ & Boltovsky et al., \\
\hline Global dominance of invasive macrophytes & Macrophytes & Freshwater & Bolpagni \\
\hline Regulation of bivalve by fish predation & Freshwater bivalve & River (experiment) & Silva et al., \\
\hline Effects of a fish invader on trophic ecology & Fish & Mesocosm & Amaral et al., \\
\hline \multicolumn{4}{|l|}{ AIS and other anthropogenic stressors } \\
\hline Modeling current and future distribution of AIS & Freshwater bivalve & Freshwater & Petsch et al., \\
\hline $\begin{array}{l}\text { AIS response to hydrological disturbance and } \\
\text { nutrients }\end{array}$ & Macrophytes & Microcosm & Zhang et al., \\
\hline $\begin{array}{l}\text { Influence of nitrate on foraging and agonistic } \\
\text { behaviors }\end{array}$ & Crayfish & Microcosm & James et al., \\
\hline Invasive fish use of artificial habitats & Fish & Reservoir & Frehse et al., \\
\hline Stress caused by Microcystis aeruginosa & Freshwater bivalve & Microcosm & $\begin{array}{l}\text { Boegehold \& } \\
\text { Kashian }\end{array}$ \\
\hline Hydrological alterations benefit AIS & Fish & River & Santos et al., (b) \\
\hline \multicolumn{4}{|l|}{ Management } \\
\hline Management and eradication of AIS & Multiple taxa & Freshwater/marine & Simberloff \\
\hline $\begin{array}{l}\text { Assessment of Dreissena population using } \\
\text { videography }\end{array}$ & Freshwater bivalve & Lakes & Karatayev et al., \\
\hline
\end{tabular}


invader, Nile tilapia (Oreochromis niloticus, Linnaeus, 1758), in Brazilian streams, which implies that aquaculture ponds are insufficiently isolated to prevent accidental escape and provide a steady source of propagules for invasion. Olden et al. (2021) show that ornamental aquarium trade via informal online marketplaces encompassed sales of hundreds of thousands of organisms and introduced a multitude of new, decentralized and difficult to regulate pathways, thereby facilitating global transport of AIS. This study highlights the increasing potential of online markets to become the new frontier of non-native species introductions in the world.

Ballast water and hull fouling are another common pathway for AIS introductions. Meloni et al. (2021) show that dry-dock sampling, or scraping the hull while the vessel is out of the water, is a more thorough approach for detection of AIS, whereas in-water assessments underestimate hull fouling diversity. A formal risk assessment of existing and potential invaders in the Mediterranean Sea emphasized the critical role of the ballast water pathway for introduction of the highest risk invaders and the need to regulate it (Stasolla et al., 2021). For sessile organisms, many of which have been initially introduced via ballast water or hull fouling, increasing marine infrastructure for oil and gas extraction is likely to provide stepping stones for future invasions and accelerate the spread of existing AIS, and this critical issue has received a completely apathetic policy response (Galil et al., 2021).

The worst high-impact invaders aside, few generalizations can be made about AIS establishment success, which is highly species-, habitat- and context-dependent (Novoa et al., 2020). Curiously, fish species more ecologically distant from resident species had greater establishment success in colder and smaller boreal lakes, whereas more ecologically similar invaders established in larger and warmer lakes (Rocha \& Cianciaruso, 2021), indicating that environmental gradients affect the outcome of invasions. Latitudinal gradients impose different environmental conditions, which may also affect AIS success. A study looking at latitudinal patterns in AIS showed that those patterns depend on the type of aquatic habitat: there was a positive correlation between species richness and latitude for marine but not freshwater AIS (Santos et al., 2021b). Habitat connectivity is often critical for establishment and spread of freshwater AIS, and floodplain lakes connected to the river had greater densities of invasive golden mussel (Limnoperna fortunei Müller, 1774) larvae than did isolated lakes, likely due to propagule sources from the river as well as greater environmental variability in isolated lakes (de Amo et al., 2021).

What distinguishes high-impact AIS?

Although increased plasticity, competitive ability and enemy release are not consistently supported for nonnative species in general (Boltovskoy et al., 2021), they are more likely to come into play for high-impact invaders. Phenotypic plasticity may confer a greater competitive advantage to high-impact AIS, particularly in a changing climate. Thiébaut et al. (2021) investigated phenotypic plasticity of an invasive water primrose (Ludwigia peploides subsp. montevidensis (Spreng.) P.H.Raven) comparing trait responses of six populations of this macrophyte that originated from the Oceanic and Mediterranean climate in France. Morphological traits of all populations were similar at the lowest temperature $\left(16^{\circ} \mathrm{C}\right)$, where their growth was very low; however, at the highest temperature $\left(30^{\circ} \mathrm{C}\right)$, Mediterranean populations produced sevenfold more biomass than the Oceanic ones. This result shows that the thermal plasticity depends on population origin and that Mediterranean populations of L. peploides are likely to have a competitive advantage in warming conditions. Greater plasticity in habitat and substrate choice was also observed in an invasive as compared to a native population of the brittle star Ophiothela mirabilis Verrill, 1867 (Tavares et al., 2021), whereas another study demonstrated a rapidly expanding fundamental niche in a freshwater dinoflagellate, Ceratium furcoides (Levander) Langhans 1925, which enables it to colonize areas outside its original climatic range (Macêdo et al., 2021). However, particular types of phenotypic plasticity, dispersal, growth and tolerance traits are difficult to generalize across AIS, e.g., even within high-impact invasive aquatic plants, these traits depended on plant growth form (Hussner et al., 2021).

Several life history characteristics, including high reproductive plasticity, ovoviviparity and the ability to reproduce parthenogenetically as well as lack of castrating parasites, which are common in its native range, may all contribute to the success of another high-impact AIS, the apple snail Potamopyrgus 
antipodarum (Gray, 1843) (Verhaegen et al., 2021). Parasite loads and diversity can vary across different populations of the same invader depending on the size of the source population, with larger founding populations more likely to harbor greater parasite diversity, as demonstrated in genetically distinct and independently introduced populations of pumpkinseed sunfish, Lepomis gibbosus (Linnaeus, 1758) in Europe (Ondračková et al., 2021). This study also highlights the potential use of parasite diversity to discriminate genetically distinct populations of non-native fishes. In another study, Liquin et al. (2021) investigated the type of interaction between the invasive mussel Limnoperna fortunei and the oligochaete Chaetogaster limnaei von Baer, 1827. Increased metabolic activity and gill damage was observed in mussels with Chaetogaster limnaei, even at low intensity of infection, an observation consistent with parasitism. However, this parasitic relationship does not seem sufficient to prevent the successful invasion of freshwaters in the La Plata Basin in South America, where this mussel has spread into several habitats.

Generalist traits are often observed in high-impact AIS (e.g., Milardi et al., 2018). In a comparison of an invasive fish Schizodon borellii (Boulenger, 1900) with its native congener in a tropical floodplain, the invader had a more generalist habitat use, greater investment in reproduction at small sizes, and larger mouth gape, indicating potential competitive advantage over the native species along multiple functional axes (Ganassin et al., 2021). These attributes seem to explain the success of the invader and its numerical dominance over the native congener. Superior feeding performance, including lower prey handling time and greater maximum feeding rates, likely contribute to an overwhelming predatory impact of invasive peacock bass, Cichla kelberi Kullander \& Ferreira (2006), in functional response experiments (Carvalho et al., 2021). Cichla is a powerful predator that invaded many ecosystems in the world, and this study is the first to show that impacts are associated with its functional response to prey availability.

\section{Impacts of AIS}

Although it is widely believed that non-native species have overwhelmingly negative effects on recipient communities and ecosystems, a review of 71 metaanalyses, which included 4822 unique primary sources on aquatic and terrestrial invaders, demonstrated that non-native species more frequently have non-significant and mixed effects on native communities (Boltovskoy et al., 2021). Because the underlying meta-analyses consider all non-native species, these findings may underestimate effects of high-impact invasives, but even for those species, there was often a mix of significant and non-significant effects (Boltovskoy et al., 2021). However, cumulative impacts of some marine AIS may have been underestimated in the underlying studies because meta-analyses tend to aggregate impacts across important opposing processes (Thomsen 2020).

Another contribution to this Special Issue provides an overview of invasive aquatic plant effects on biodiversity, biological interactions and metabolic and ecophysiological processes (Bolpagni, 2021). This review focuses on several examples of high-impact macrophytes and emphasizes that an ecosystem-based perspective is necessary to properly understand the implications of plant invaders in freshwaters. Similar negative impacts have been shown for invasive invertebrates and fish. For example, the invasive golden mussel (Limnoperna fortunei) had strong negative effects on the total density of native benthic macroinvertebrates, in particular scrapers, dipterans and gastropods; however, native fish predation on the invader mitigated these effects and promoted native invertebrate persistence (Silva et al., 2021). Invasive piscivorous fish Schizodon borellii likely contributed to the dramatic recent decline of its native congener $S$. altoparanae in the Paraná River (Ganassin et al., 2021). An experiment simulating an early stage of invasion demonstrated that both an invasive (Poecilia reticulata) and a native fish species (Phalloceros harpagos) experienced a decrease in individual trophic niche (Amaral et al., 2021), suggesting that there can be individual-level trophic changes even in the absence of population-level effects.

Beyond their impacts on communities and ecosystems, many AIS also have considerable effects on cultural, habitat and provisioning ecosystem services. Some AIS, such as several invaders in the Mediterranean including lionfish (Pterois miles Bennett, 1828) and nomadic jellyfish (Rhopilema nomadica Galil, Spanier \& Ferguson, 1990), can also pose direct threats to human health and have enormous consequences for fisheries and recreation (Galil et al., 2021). 
Interactions with other anthropogenic stressors

A variety of anthropogenic stressors, from eutrophication and habitat destruction to climate change, can affect AIS establishment success, rate of spread and dominance in native communities (e.g., Rahel \& Olden, 2008, Catford et al., 2009). Six papers of this SI focused specifically on how stressors influence AIS success. The review by Bolpagni (2021) shows that eutrophication and hydromorphological alterations affect the success of several species of invasive aquatic plants. Ecological niche models demonstrated that climate change may increase habitat availability for golden mussel in the New World (Petsch et al., 2021). High-nutrient substrates and water level fluctuations, a common problem in managed lakes and reservoirs, increased biomass accumulation in invasive parrot feather milfoil (Myriophyllum aquaticum (Vell.) Verdcourt); however, these effects were complex and confounded by depth and frequency of water level fluctuations (Zhang et al., 2021). Another study showed that increased nitrate concentrations decreased agonistic interactions between two invasive crayfish species and reduced their foraging efficiency, which is likely to have complex effects on invasion dynamics (James et al., 2021). Harmful algal blooms (HABs), increasing in frequency with eutrophication, can also shift the balance between invasive and native species as well as between the different invasive species, depending on their tolerance. Quagga mussels, Dreissena rostriformis bugensis (Andrusov, 1897), were more sensitive to HAB-associated cyanobacterial toxin microcystin than were Asian clams, Corbicula fluminea (Müller, 1774), which can have large-scale effects on the distribution of these two invasive species (Boegehold \& Kashian, 2021).

Hydrological alterations including changes in flow regime (dams, reservoirs) and water abstraction are some of the key stressors affecting native freshwater biodiversity, and these alterations often favor invasive species and lead to homogenization of freshwater faunas (e.g., Havel et al., 2015). Reservoirs increase establishment and dominance of AIS (e.g., Havel et al., 2015), and some types of artificial structures used to enhance fish habitat in reservoirs seem to preferentially benefit invasive fish (Frehse et al., 2021). A comparison of natural and anthropogenically modified (by damming, channelization and drained floodplains) stretches of a coastal river in Brazil found that non-native species occurred mainly in the disturbed stretches (Santos et al., 2021a). In contrast, several native species were found only in the natural stretches (Santos et al., 2021a), demonstrating the importance of preserving natural hydrologic regimes and the least modified aquatic ecosystems to reduce invasions and protect native fish biodiversity.

Management of invasive species

Managing and eradicating invasive species is one of the greatest challenges in the field of invasion biology. The efforts to eradicate or manage freshwater and marine aquatic invasive species were extensively reviewed by Simberloff (2021), who summarized results obtained using several established approaches as well as new methods currently in development (including advances in molecular genetics). There are many examples of successful and failed eradication and management efforts; however, more instances of successful control have been observed with recent, localized invasions (Simberloff, 2021). Maintenance management of freshwater fish invaders tended to be more successful than that for aquatic plants, and marine invasions tend to be even more difficult to manage than those in freshwater habitats (Simberloff, 2021). Risk assessment can be useful for prioritizing monitoring and early eradication of the highest risk invaders (Stasolla et al., 2021), especially in areas with recognized invasion debt, or a clear lag between establishment and spread (Galil et al., 2021). Monitoring and eradication efforts may benefit from more precise mapping of the spatial distribution of invasive species, such as underwater remote sensing approaches for detection and quantification of zebra mussels (Karatayev et al., 2021). Promising new approaches for managing AIS include gene-silencing, RNA-guided gene drives, and the use of transgenes as well as non-genetic approaches such as pheromone and sterile male techniques (Simberloff, 2021). Because the vectors of introduction of AIS are expected to further expand and diversify (Seebens et al., 2018), invasion biology has an important role to play in finding new and more efficient ways to reverse this trend and minimize the damage caused by already established invasive species. 


\section{Search volume trends}

Public interest is paramount to all aspects of AIS research and management, from legislation to prevent new introductions to research funding allocation to public acceptance of AIS control (e.g., Verbrugge et al., 2013, Novoa et al., 2017, Höbart et al., 2020). However, interest and awareness are very difficult to capture in traditional surveys because the nonresponse rate is likely to be highly correlated with lack of interest or topic recognition. Internet search volumes, or the number of user queries using a certain keyword, on the other hand, have been shown to closely mirror public interest and awareness and have been successfully employed in multiple fields (e.g., Ripberger 2011; Ladle et al., 2016; Soriano-Redondo et al., 2017).

Analysis of search volumes, including Google Trends (GT), has been used in conservation biology to track phenology, identify conservation emblems, demonstrate public response to conservation actions and shifts in public opinion (Proulx et al., 2013; Ladle et al., 2016). This approach, alternatively known as culturomics, has also been applied to invasive species in general (Mccallum \& Bury, 2013; Proulx et al., 2013; Nghiem et al., 2016), but to the best of our knowledge it has not been used to analyze detailed trends in aquatic invasive species. Previous studies presented somewhat conflicting trends in search volumes for invasive species (hereafter we will use italics to designate specific search keywords analyzed) using different approaches: a moderate decline over time was observed with normalized search volumes (range of data: 2001-2009, Mccallum \& Bury, 2013), whereas a benchmarked search showed an increase in interest (2004-2013, Nghiem et al., 2016). Normalized search volumes, such as those released by GT, are the search volumes for each term expressed as a proportion of all searches on all topics. Although this approach allows analyses of the relative importance of particular keywords, it is not ideal for discussion of absolute trends. An alternative approach, using benchmarks, or searches adjusted by neutral keywords interest in which is assumed to stay constant over time, can also be biased by benchmark aging or speciation, or increasing precision of search terminology (e.g., fewer people are likely to search for computer or software than a specific brand, and these supposedly neutral benchmarks indeed show a drastic decline in search volume, data not shown).

Here we analyze absolute changes in multiple invasive species-related keywords to gauge public interest in AIS in general and in specific invaders, to evaluate the relative importance of different AIS terms and to compare interest in invasive species and other environmental issues. We used the Keywords Everywhere app with Google Chrome to analyze absolute search volumes. Keywords Everywhere (https:// keywordseverywhere.com/) works by reverse-engineering Google Trends data to de-normalize the data and provide exact raw search volumes. The search period covered all available data for the 17 years from January 2004 to December 2020. Most search terms had sufficient data for quantitative trends analysis unless indicated otherwise. Keywords Everywhere provides monthly search data, but, in most cases, we analyzed data aggregated by year to optimize visualization of annual trends over small-scale periodicity. Temporal trends in different keywords were analyzed using linear and Generalized Additive models. All analyses were done in $\mathrm{R}$ (version 4.0.2; $\mathrm{R}$ Core Development Team 2020).

Search volumes for high-impact AIS

Overall, search volume for invasive species has been increasing over time (Fig. $1, P<0.0001$ ), whereas aquatic invasive species had a much lower overall search volume and tended to decrease (or else the trend was skewed by a few very high values at the beginning of the time series, see below). Not surprisingly, increasing text string length and the number of keywords yield fewer successful searches, which at least partly explains the lower number of searches for the longer keyword aquatic invasive species.

An increasing public interest in invasive species, however, is expected to not only result in greater search volumes for that specific keyword, but to lead to diversification of keywords and to an increasing number of inquiries into specific high-impact AIS. It was beyond the scope of this study to examine AIS ranked by ecological importance or public awareness, but we compared search volume trends for several well-known high-impact AIS in North America including lionfish (Pterois sp.), grass carp (Ctenopharyngodon idella Steindachner, 1866), Asian carp (common keyword collectively referring 
Fig. 1 Temporal trends in search volumes for keywords invasive species and aquatic invasive species Data are annual absolute search volumes, fitted with a generalized additive model (GAM)

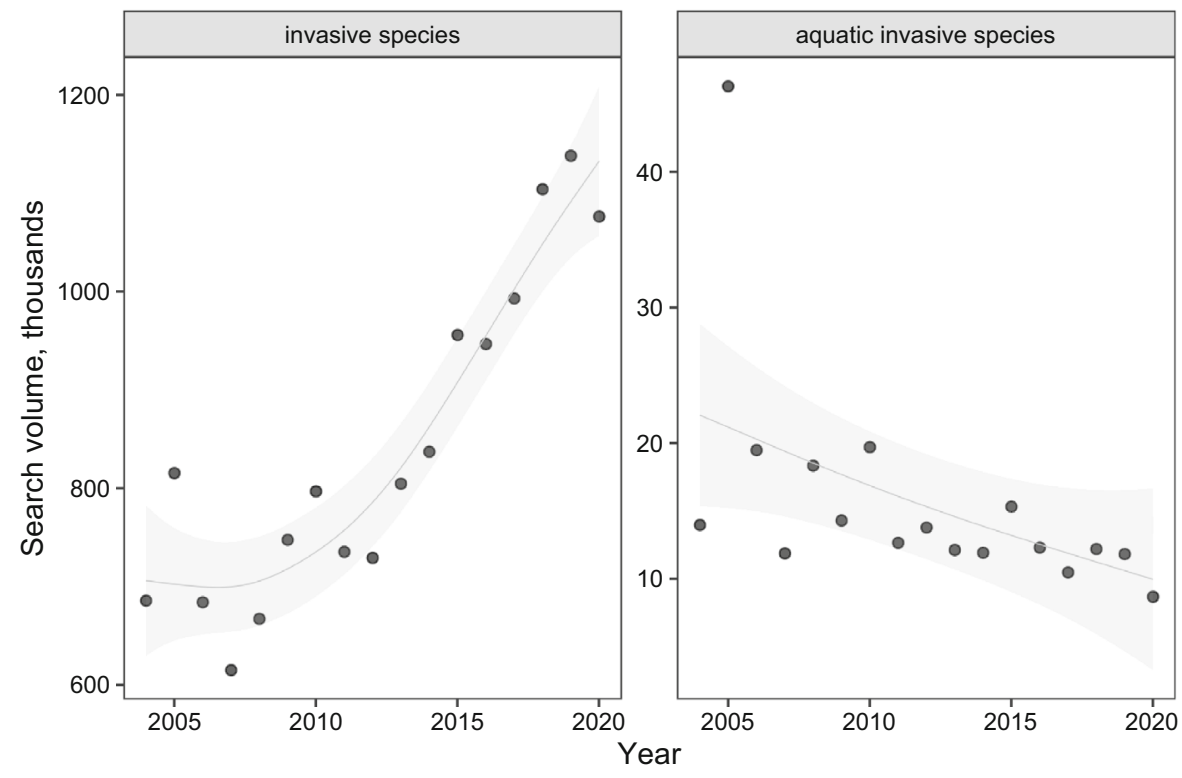

to Hypophthalmichthys nobilis (Richardson, 1845), $H$. molitrix (Valenciennes, 1844), C. idella, and Mylopharyngodon piceus (J. Richardson, 1846)), zebra mussels Dreissena polymorpha (Pallas, 1771), and Phragmites (Phragmites australis (Cav.) Trin ex. Steud., or common reed, which is commonly referred to by genus name).

Indeed, searches for a subset of high-impact AIS have greatly surpassed searches for aquatic invasive species and even invasive species (Fig. 2). For example, lionfish has nearly 3 times the search volume of invasive species in the last 2 years, whereas grass carp and invasive species were similar to invasive species in total search volume. Marine global AIS lionfish search volumes were twofold greater than the next mostsearched AIS (grass carp and Asian carp), and steadily increasing $(P<0.0001)$, which could be attributed to lionfish recent expansion in the Atlantic and because of the human health risk posed by this venomous species (e.g., Resiere et al., 2016). Other species-specific trends appear to be relatively stable (e.g., grass carp) or in moderate decline (e.g., zebra mussels), which could be explained by their relatively long presence in the invaded ecosystems or possibly skewed by a few very high values early in the time series.

Public awareness of prevention campaigns is critical for their successful implementation. Yet search volumes for management-related keywords were considerably lower, likely because of greater keyword length and complexity. Prevention logo stop aquatic hitchhikers (from a public awareness campaign in the USA) did not pass a threshold search volume to be indexed, whereas clean drain dry, which is frequently used in public education campaigns to prevent boating- and fishing-related introductions, appeared slightly more popular. We also analyzed trends for four other keywords likely to be used by someone interested in AIS prevention and control (prevent invasive species, invasive species control, stop invasive species, and invasive species prevention). Of these, prevent invasive species was the most popular and increasing (Fig. 3), but still constituted only a small fraction ( $0.4 \%$ over the last 2 years) of the total search volume for invasive species. Although less popular, stop invasive species has also increased, while the search volumes of the two other keywords remained nearly constant overtime (Fig. 3). It is possible that some of this information is accessed indirectly and is therefore not captured in GT. For example, AIS regulations can be linked from Departments of Natural Resources, boating and fishing licensing and other aquatic recreation-related websites.

Trends in AIS interest compared with other environmental issues

Total search volume for invasive species and highimpact AIS (e.g., grass carp) was comparable to other 

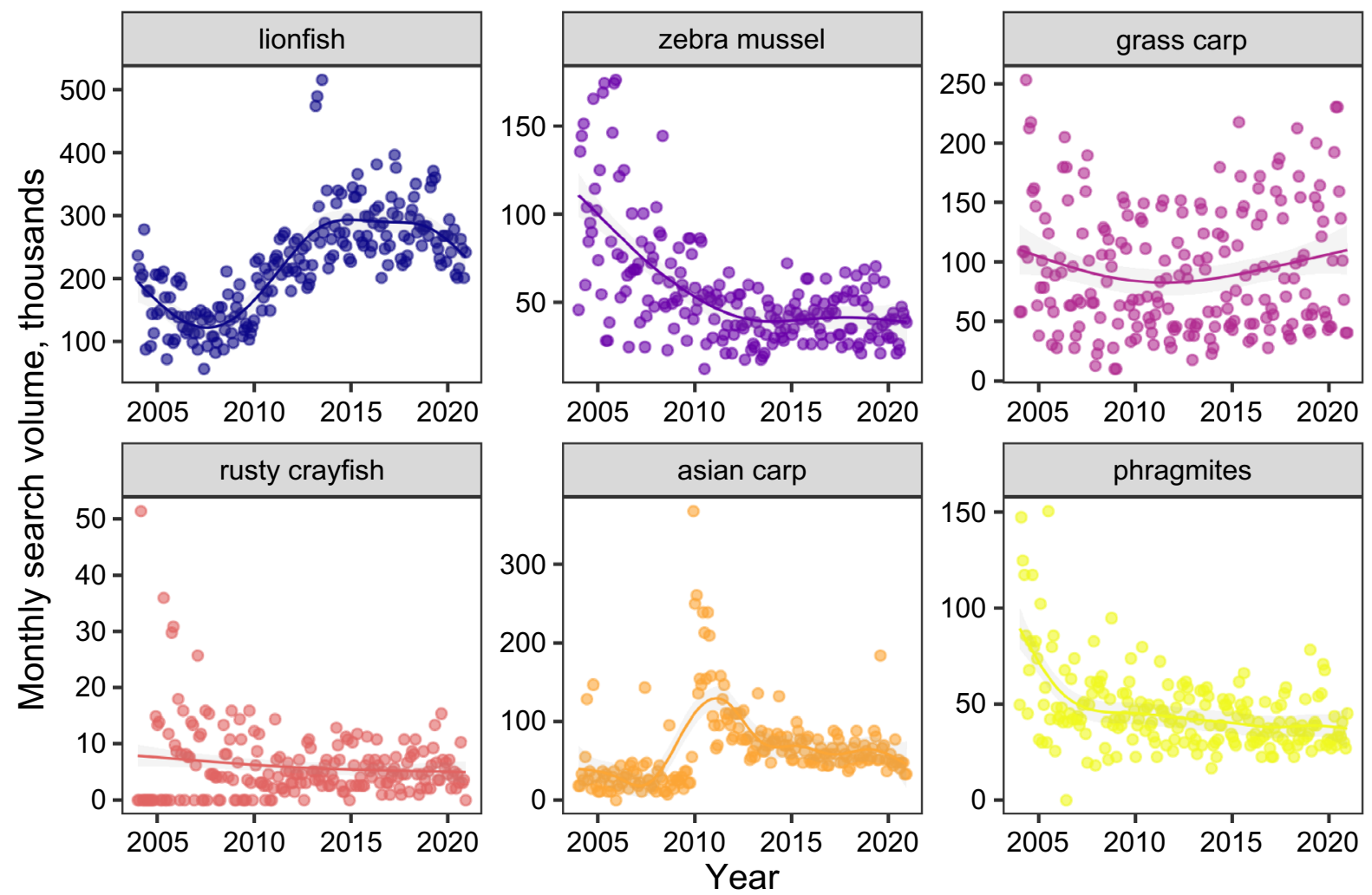

Fig. 2 Search volume for several high-impact AIS, presented as raw monthly data to illustrate variability and fitted with a generalized additive model (GAM)

Fig. 3 Prevention and management-related keyword search volumes. Data are annual absolute search volumes, fitted with a generalized additive model (GAM)

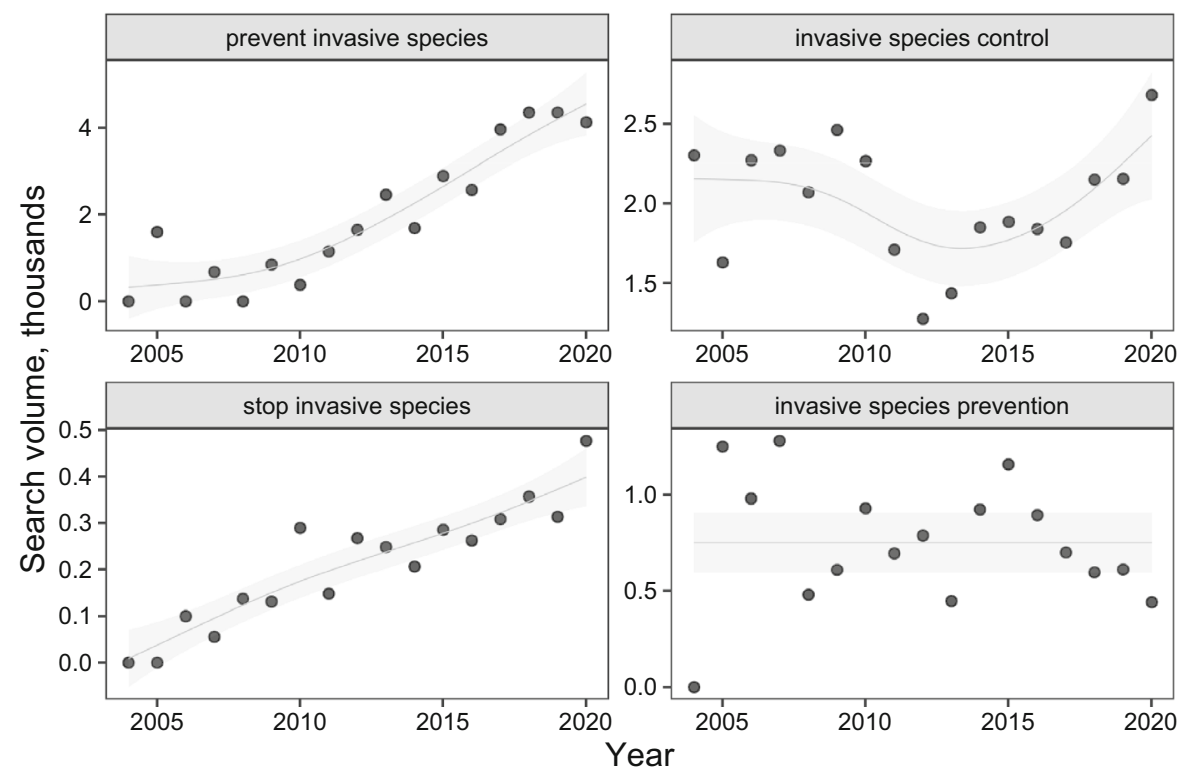

more general keywords commonly associated with interest in or awareness of environmental issues in aquatic environments (biodiversity, eutrophication, algal blooms, freshwater fish, Fig. 4) but were lower 
than others (water pollution, fishing). Water pollution is a keyword which is not limited to aquatic ecology and is likely linked to drinking water, purification technologies and other areas, whereas fishing is a short, hobby-associated keyword, so it is not surprising that these two terms, representing much broader perspectives and themes, have much higher search volumes. Trends in most of these search terms were notably non-linear compared to a mostly linear increasing trend in invasive species (Fig. 4).

Alternative terminology search volumes

Aquatic invasive species research has been plagued by inconsistent terminology and, despite multiple attempts at standardization, several terms have been used interchangeably (Richardson et al., 2011). Although we advocate consistent terminology for scientific studies (Havel et al., 2015), here we compared public interest in those terms to better guide outreach efforts for future studies. This analysis focused on all invasive species (not just AIS) to increase data volume. It appears that invasive species is the preferred term based on the overall search volume (Fig. 5), and its usage has significantly increased over time $\left(R^{2}=0.77, P<0.0001\right)$. It was followed by a much less popular term exotic species, which has declined, whereas alien, introduced, nonnative and nuisance species comprised a negligible proportion of the search volume for the preferred term, invasive species. Other alternative keywords, nonnative invasive, invasive alien and non-indigenous species were likewise of minor importance (Fig. 5), and the former had such low search volumes that it could not be analyzed. Other types of surveys confirm trends in usage of AIS terminology (Kapitza et al., 2019). It may be timely to reiterate that these terms are certainly not synonyms but are contrasted here to evaluate public usage. This comparison nevertheless

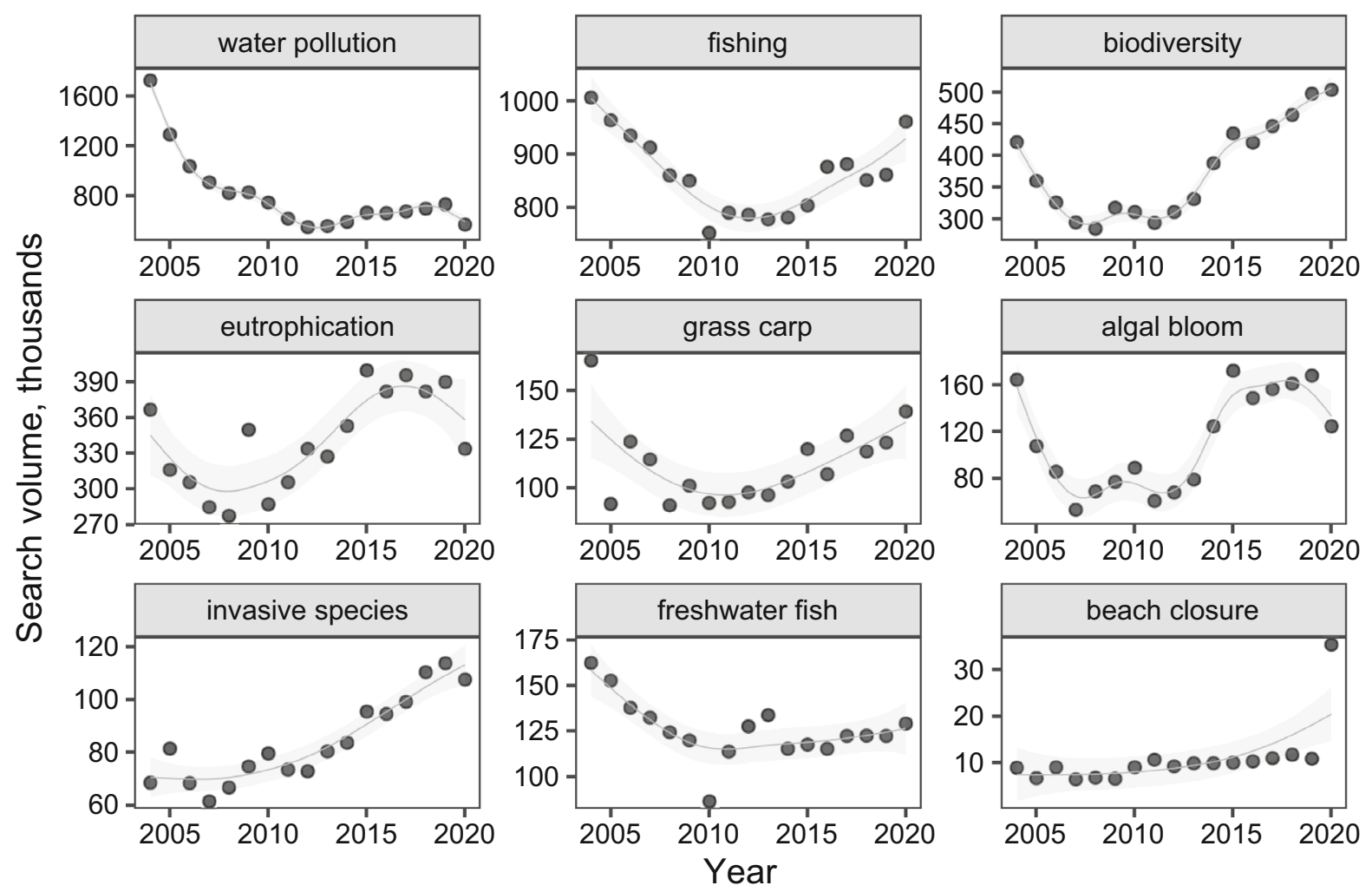

Fig. 4 Search volume for invasive species compared to several other common keywords indicative of awareness of issues or interest in aquatic ecosystems (with the exception of the more general keyword biodiversity). Data are annual absolute search volumes, fitted with a generalized additive model (GAM) 


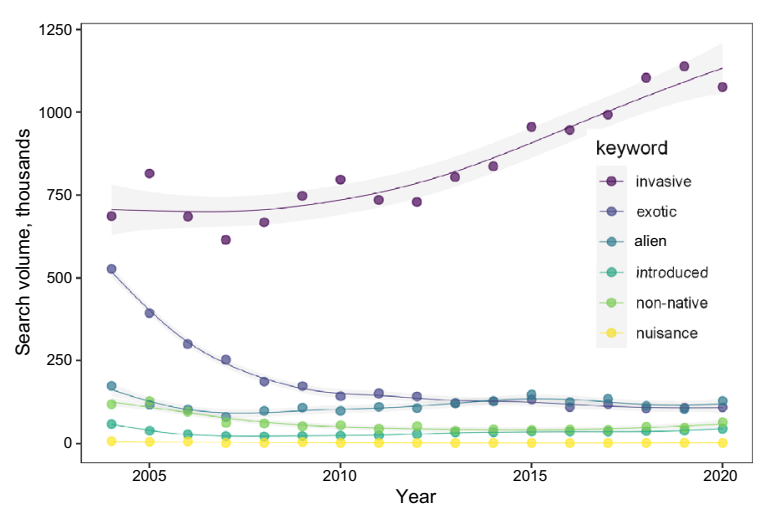

Fig. 5 Temporal trends in alternative keyword use. Data are annual absolute search volumes, fitted with a generalized additive model (GAM)

provides important insights into translating research findings for public consumption.

\section{Discussion}

Absolute total search volume for invasive species has steadily increased over time, whereas search volumes for high-impact invaders, which often surpassed invasive species in median volume, exhibited species-specific trends. Increased public interest in AIS can lead to greater compliance with regulations to prevent the spread of AIS and greater acceptance of control measures (e.g., Sharp et al., 2011; Novoa et al., 2017; Van Riper et al., 2019), and informed citizens can even contribute to early detection of new populations of AIS (Fukano \& Soga, 2017). This and other types of culturomics analyses can be a starting point for understanding how research findings percolate to the general public, how internet users may be searching for information in a specific field, how to increase target audience inclusivity and how the research community can maintain this interest and bridge the gap to outreach and implementation. Our results also demonstrate that biodiversity search volume is certainly not declining, contributing to the debate about effects of data transformations on the analysis of this critical trend (Mccallum \& Bury, 2013 vs. Funk \& Rusowsky, 2014; Nghiem et al., 2016; Troumbis 2017; Burivalova et al., 2018).

This approach can be extended to other AIS and languages to gauge public interest in different AIS or be taken further to understand its drivers. Keywords must be chosen with care to avoid, on one hand, ambiguity and, on the other hand, long and esoteric keywords, which are unlikely to be used by the general public and usually do not yield high search volumes (e.g., freshwater conservation, marine biodiversity, freshwater ecosystem services). Some of the keywords used in the previous studies such as conservation can be used in multiple contexts and are ambiguous without additional modifiers, whereas certain species (e.g., largemouth bass, grass carp) can be searched for by those concerned about their invasion potential or by those interested in sport fishing or aquaculture.

High-resolution weekly trends can be used to measure difference in interest on time scales which correspond to particular news releases and specific projects (e.g., see Soriano-Redondo et al., 2017 for conservation examples). The relationship between news releases and invasive species interest has been demonstrated in global (Nghiem et al., 2016) and regional studies. For example, spatial distribution of relative search volumes for invasive species in Japan was predicted by distribution of invasives and their coverage in news articles (Fukano \& Soga, 2017) and spatial distribution of searches for Asian carp in the USA reflected public concern about the spread of these invaders into the Laurentian Great Lakes (Proulx et al., 2013). This close connection between news, outreach and recognition of AIS places additional emphasis on keeping public engagement at the forefront of AIS research. Although this is difficult to evaluate quantitatively, it is plausible that AIS outreach and mass media coverage creates a positive feedback loop, resulting in greater problem recognition and greater media interest. If this is the case, it may serve as an example for outreach and public engagement for other important issues in freshwater and marine conservation.

This analysis is subject to several potential limitations. Most importantly, GT analyzed here are limited by the primary search language for the obvious reason that public searches are more likely to be done in a native language, and searches in other languages may show different trends (e.g., Funk \& Rusowski, 2014). Other limitations include sampling only a proportion of searches (because other search engines do not release search volumes), missing part of the population not actively using internet search engines, and keyword semantics and ambiguity (Ladle et al., 2016; Troumbis \& Iosifidis 2020). GT data are generated 
using proprietary algorithms, and changes in those algorithms can have untraceable consequences for search repeatability. Only volumetric searches that pass a certain threshold are indexed using this algorithm, so zero values may not indicate zero search activity, which can lead to underestimation of monthly volumes for the less common keywords. In addition, many search terms had very high search volumes at the beginning of the indexing period (2004-2005), which could be a coincidence or may indicate an internal indexing issue. Direct use of keywords is not the only indication of interest, as users could be accessing relevant information by following links from other sources (this may be captured in Google Trends Topic vs. Search Terms, but absolute search volumes for Topic could not be quantitatively assessed using Keywords Everywhere app). In addition, we did not attempt an exhaustive identification of the most important keywords for aquatic ecology or conservation, and our choice of keywords does not imply they were the highest ranking. Nevertheless, we believe that, with those limitations in mind, these results can be used to gauge public interest in multiple aspects of AIS research.

Public interest in aquatic invasive species correlates with education level and active use of water bodies for recreation and sport fishing (Eiswerth et al., 2011; Nanayakkara et al., 2018). Outreach activities, which are often targeted at these users for the perfectly valid reason of minimizing the spread of AIS, can nevertheless further exacerbate this disparity, and should perhaps be targeting wider user groups in the future to ensure more inclusive public participation.

In summary, we show that public interest in invasive species is mostly unabating and often compares favorably to other environmental issues. Sustaining and diversifying this interest is vital to the success of AIS prevention and management campaigns.

Acknowledgments We are grateful to Valerie Brady, Lucinda Johnson and two anonymous reviewers for their comments on the earlier version of this manuscript and to Koen Martens for serving as an editor on this submission.

Funding NA

Data availability Data available from Google Trends, Keywords Everywhere or authors upon request.

\section{Declarations}

Conflict of interest The authors declare that they have no conflict of interest.

\section{References}

Amaral, J. R., L. R. Manna, R. Mazzoni, V. Neres-Lima, P. S. Marques, R. El-Sabaawi \& E. Zandona, 2021. Testing the short-term effects of a fish invader on the trophic ecology of a closely related species. Hydrobiologia. https:// doi.org/10.1007/s10750-020-04489-3.

Anton, A., N. R. Geraldi, C. E. Lovelock, et al., 2019. Global ecological impacts of marine exotic species. Nature Ecology and Evolution 3: 787-800.

Boegehold, A. G. \& D. R. Kashian, 2021. Stress tolerance of two freshwater invaders exposed to Microcystis aeruginosa and microcystin-LR. Hydrobiologia. https://doi.org/10.1007/ s10750-020-04511-8.

Bolpagni, R., 2021. Towards global dominance of invasive alien plants in freshwater ecosystems: the dawn of the Exocene? Hydrobiologia. https://doi.org/10.1007/s10750-02004490-w.

Boltovskoy, D., N. M. Correa, L. E. Burlakova, A. Y. Karatayev, E. V. Thuesen, F. Sylvester \& E. M. Paolucci, 2021. Traits and impacts of introduced species: a quantitative review of meta-analyses. Hydrobiologia. https://doi.org/10.1007/ s10750-020-04378-9.

Burivalova, Z., R. A. Butler \& D. S. Wilcove, 2018. Analyzing Google search data to debunk myths about the public's interest in conservation. Frontiers in Ecology and the Environment 16: 509-514.

Carvalho, T. L., E. de Almeida Ferreira, F. M. Pelicice \& R. Fernandes, 2021. Comparative functional responses predict the predatory impact of the highly invasive fish Cichla kelberi. Hydrobiologia. https://doi.org/10.1007/s10750020-04440-6.

Catford, J. A., R. Jansson \& C. Nilsson, 2009. Reducing redundancy in invasion ecology by integrating hypotheses into a single theoretical framework. Diversity and Distributions 15: 22-40.

Corrales, X., S. Katsanevakis, M. Coll, J. J. Heymans, C. Piroddi, E. Ofir \& G. Gal, 2020. Advances and challenges in modelling the impacts of invasive alien species on aquatic ecosystems. Biological Invasions 22: 907-934.

David, P., E. Thiebault, O. Anneville, P.-F. Duyck, E. Chapuis $\&$ N. Loeuille, 2017. Impacts of invasive species on food webs: a review of empirical data. Advances in Ecological Research 56: 1-60.

de Amo, V. E., J. Ernandes-Silva, D. A. Moi \& R. P. Murmul, 2021. Hydrological connectivity drives propagule pressure of Limnoperna fortunei (Dunker, 1857) in a tropical riverfloodplain system. Hydrobiologia. https://doi.org/10.1007/ s10750-021-04543-8.

Dueñas, M.-A., H. J. Ruffhead, N. H. Wakefield, P. D. Roberts, D. J. Hemming \& H. Diaz-Soltero, 2018. The role played by invasive species in interactions with endangered and threatened species in the United States: a systematic review. Biodiversity and Conservation 27: 3171-3183. 
Eiswerth, M. E., S. T. Yen \& G. C. van Kooten, 2011. Factors determining awareness and knowledge of aquatic invasive species. Ecological Economics 70: 1672-1679.

Forneck, S. C., F. M. Dutra, M. P. Camargo, J. R. S. Vitule \& A. M. Cunico, 2021. Aquaculture facilities drive the introduction and establishment of non-native Oreochromis niloticus populations in Neotropical streams. Hydrobiologia. https://doi.org/10.1007/s10750-020-04430-8.

Frehse, F., O. L. F. Weyl \& J. R. S. Vitule, 2021. Differential use of artificial habitats by native and non-native fish species in Neotropical reservoirs. Hydrobiologia. https://doi.org/10. 1007/s10750-021-04564-3.

Fukano, Y. \& M. Soga, 2017. Spatio-temporal dynamics and drivers of public interest in invasive alien species. Biological Invasions 21: 3521-3532.

Funk, S. M. \& D. Rusowsky, 2014. The importance of cultural knowledge and scale for analysing internet search data as a proxy for public interest toward the environment. Biodiversity and Conservation 23: 3101-3112.

Galil, B. S., H. K. Mienis, R. Hoffman \& M. Goren, 2021. Nonindigenous species along the Israeli Mediterranean coast: tally, policy, outlook. Hydrobiologia. https://doi.org/10. 1007/s10750-020-04420-w.

Gallardo, B., M. Clavero, M. I. Sánchez \& M. Vilà, 2016. Global ecological impacts of invasive species in aquatic ecosystems. Global Change Biology 22: 151-163.

Ganassin, M. J. M., E. García-Berthou, A. C. Rodrigues, C. Pedrozo do Nascimento, C. M. Muniz, M. T. Baumgartner, M. H. Schmitz \& L. C. Gomes, 2021. The invasion of an alien characiform fish and the decline of a native congener in a Neotropical river-floodplain system. Hydrobiologia. https://doi.org/10.1007/s10750-020-04454-0.

Geller, I. V., D. A. Z. Garcia, A. C. R. Casimiro, et al., 2020. Good intentions, but bad effects: environmental laws protects non-native ichthyofauna in Brazil. Fisheries Management and Ecology 28: 14-17.

Giakoumi, S., S. Katsanevakis, P. G. Albano, E. Azzurro, A. C. Cardoso, E. Cebrian, A. Deidun, D. Edelist, P. Francour, C. Jimenez, V. Mačić, A. Occhipinti-Ambrogi, G. Rilov \& Y. R. Sghaier, 2019. Management priorities for marine invasive species. Science of the Total Environment 688: 976-982.

Goedknegt, M. A., M. E. Feis, K. M. Wegner, P. C. Luttikhuizen, C. Buschbaum, K. Camphuysen, J. van der Meer $\&$ D. W. Thieltges, 2016. Parasites and marine invasions: ecological and evolutionary perspectives. Journal of Sea Research 113: 11-27.

Guy-Haim, T., D. A. Lyons, J. Kotta, et al., 2018. Diverse effects of invasive ecosystem engineers on marine biodiversity and ecosystem functions: a global review and meta-analysis. Global Change Biology 24: 906-924.

Havel, J. E., K. E. Kovalenko, S. M. Thomaz, S. Amalfitano \& L. B. Kats, 2015. Aquatic invasive species: challenges for the future. Hydrobiologia 750: 147-170.

Havel, J. E., S. M. Thomaz, L. B. Kats, K. E. Kovalenko \& L. N. Santos, 2018. Aquatic invasive species: preface to the special issue. Hydrobiologia 817: 1-9.

Höbart, R., S. Schindler \& F. Essl, 2020. Perceptions of alien plants and animals and acceptance of control methods among different societal groups. NeoBiota 58: 33-54.
Hussner, A., P. Heidbüchel, J. Coetzee \& E. M. Gross, 2021. From introduction to nuisance growth: a review of traits of alien aquatic plants which contribute to their invasiveness. Hydrobiologia. https://doi.org/10.1007/s10750-02004463-z.

James, J., J. R. Thomas, A. Maceda-Veiga, R. Mitchell, I. P. Vaughan \& J. Cable, 2021. Environmental nitrate impacts foraging and agonistic behaviours of invasive nonnative crayfish (Pacifastacus leniusculus and Faxionus virilis). Hydrobiologia. https://doi.org/10.1007/s10750020-04488-4.

Kapitza, K., H. Zimmermann, B. Martín-López \& H. von Wehrden, 2019. Research on the social perception of invasive species: a systematic literature review. NeoBiota 43: 47-68.

Karatayev, A. Y., L. E. Burlakova, K. Mehler, E. K. Hinchey, M. Wick, M. Bakowska \& N. Mrozinska, 2021. Rapid assessment of Dreissena population in Lake Erie using underwater videography. Hydrobiologia. https://doi.org/ 10.1007/s10750-020-04481-X.

Ladle, R. J., R. A. Correia, Y. Do, G.-J. Joo, A. C. M. Malhado, R. Proulx, J.-M. Roberge \& P. Jepson, 2016. Conservation culturomics. Frontiers in Ecology and Environment 14: 269-275.

Lennox, R., K. Choi, P. M. Harrison, J. E. Paterson, T. B. Peat, T. D. Ward \& S. J. Cooke, 2015. Improving science-based invasive species management with physiological knowledge, concepts, and tools. Biological Invasions 17: 2213-2227.

Liquin, F., L. A. Hünicken, F. Arrighetti, D. Davies, E. M. Paolucci \& F. Sylvester, 2021. Parasitism and fitness of invaders: oligochaete Chaetogaster limnaei produces gill damage and increased respiration rates in freshwater Asian clams. Hydrobiologia. https://doi.org/10.1007/s10750020-04424-6.

Macêdo, R. L., P. Russo, R. F. Corrêa, O. Rocha, L. N. dos Santos \& C. W. C. Branco, 2021. The drifting dinoflagellate Ceratium furcoides (Levander) Langhans 1925: fundamental niche shift during global invasion. Hydrobiologia. https://doi.org/10.1007/s10750-02004495-5.

Magalhães, A. L. B., V. S. Daga, L. A. V. Bezerra, J. R. S. Vitule, C. M. Jacobi \& L. G. M. Silva, 2020. All the colors of the world: biotic homogenization-differentiation dynamics of freshwater fish communities on demand of the Brazilian aquarium trade. Hydrobiologia 847: 3897-3915.

Mccallum, M. L. \& G. W. Bury, 2013. Google search patterns suggest declining interest in the environment. Biodiversity and Conservation 22: 1355-1367.

Meloni, M., N. Correa, F. B. Pitombo, I. L. Chiesa, B. Doti, R. Elías, G. Genzano, C. B. Giachetti, D. Giménez, J. LópezGappa, C. Pastor, A. P. Wandeness, F. C. Ramírez, D. Roccatagliata, M. Schulze-Sylvester, M. Tatián, D. G. Zelaya \& F. Sylvester, 2021. In-water and dry-dock hull fouling assessments reveal high risk for regional translocation of nonindigenous species in the southwestern Atlantic. Hydrobiologia. https://doi.org/10.1007/s10750020-04345-4.

Milardi, M., M. Lanzoni, A. Gavioli, E. A. Fano \& G. Castaldelli, 2018. Long-term fish monitoring underlines a rising tide of temperature tolerant, rheophilic, benthivore and 
generalist exotics, irrespective of hydrological conditions. Journal of Limnology 77: 266-275.

Nanayakkara, L., R. Jurdi-Hage, P. R. Leavitt \& B. Wissel, 2018. In lakes but not in minds: stakeholder knowledge of invasive species in prairie lakes. Biological Invasions 20: 633-652.

Nghiem, L. T. P., S. K. Papworth, F. K. S. Lim \& L. R. Carrasco, 2016. Analysis of the capacity of Google Trends to measure Interest in conservation topics and the role of online news. PLoS ONE 11: https://doi.org/10.1371/journal.pone. 0152802.

Novoa, A., K. Dehnen-Schmutz, J. Fried \& G. Vimercati, 2017. Does public awareness increase support for invasive species management? Promising evidence across taxa and landscape types. Biological Invasions 19: 3691-3705.

Novoa, A., D. M. Richardson, P. Pyšek, et al., 2020. Invasion syndromes: a systematic approach for predicting biological invasions and facilitating effective management. Biological Invasions 22: 1801-1820.

Olden, J. D., E. Whattam \& S. A. Wood, 2021. Online auction marketplaces as a global pathway for aquatic invasive species. Hydrobiologia. https://doi.org/10.1007/s10750020-04407-7.

Ondračková, M., V. Bartáková, Y. Kvach, A. Bryjová, T. Trichkova, F. Ribeiro, L. Carassou, A. Martens, G. Masson, T. Zechmeister \& P. Jurajda, 2021. Parasite infection reflects host genetic diversity among nonnative populations of pumpkinseed sunfish in Europe. Hydrobiologia. https:// doi.org/10.1007/s10750-020-04410-y.

Pelicice, F. M., V. M. Azevedo-Santos, J. R. S. Vitule, et al., 2017. Neotropical freshwater fishes imperiled by unsustainable policies. Fish and Fisheries 18: 1119-1133.

Petsch, D. K., L. G. dos Santos Ribas, T. Mantovano, M. M. Pulzatto, A. T. Alves, G. D. Pinha \& S. M. Thomaz, 2021. Invasive potential of golden and zebra mussels in present and future climatic scenarios in the new world. Hydrobiologia. https://doi.org/10.1007/s10750-02004412-w.

Proulx, R., P. Massicotte \& M. Pépino, 2013. Googling trends in conservation biology. Conservation Biology 28: 44-51.

Rahel, F. J. \& J. D. Olden, 2008. Assessing the effects of climate change on aquatic invasive species. Conservation Biology 22: 521-533.

Resiere, D., L. Cerland, L. De Haro, R. Valentino, A. CriquetHayot, C. Chabartier, S. Kaidomar, Y. Brouste, B. Megarbane \& H. Mehdaoui, 2016. Envenomation by the invasive Pterois volitans species (lionfish) in the French West Indies - a two-year prospective study in Martinique. Clinical Toxicology 54: 313-318.

Richardson, D. M., P. Pyšek \& J. T. Carlton, 2011. A compendium of essential concepts and terminology in invasion ecology. In Richardson, D. M. (ed.), Fifty Years of Invasion Ecology: The Legacy of Charles Elton, 1st ed. Blackwell Publishing Ltd, Hoboken: 409-420.

Ripberger, J. T., 2011. Capturing curiosity: using internet search trends to measure public attentiveness. The Policy Studies 39: 239-259.

Rocha, B. S. \& M. V. Cianciaruso, 2021. Water temperature and lake size explain Darwin's conundrum for fish establishment in boreal lakes. Hydrobiologia. https://doi.org/10. 1007/s10750-020-04434-4.
Santos, V. L. M., P. A. Catelani, A. C. Petry \& E. M. P. Caramaschi, 2021a. Hydrological alterations enhance fish invasions: lessons from a Neotropical coastal river. Hydrobiologia. https://doi.org/10.1007/s10750-02104542-9.

Santos, L. N., A. C. S. Franco, J. S. de Souza, et al., 2021b. Using richness of native and non-native aquatic species along a climatic gradient to test the Intermediate Disturbance Hypothesis. Hydrobiologia. https://doi.org/10.1007/ s10750-021-04525-w.

Sax, D. F., J. J. Stachowicz \& S. D. Gaines (eds), 2005. Species Invasions: Insights into Ecology, Evolution, and Biogeography. Sinauer Associates, Inc., Sunderland: 495.

Seebens, H., T. M. Blackburn, E. E. Dyer, et al., 2017. No saturation in the accumulation of alien species worldwide. Nature Communications 8: 14435.

Seebens, H., T. M. Blackburn, E. E. Dyer, et al., 2018. Global rise in emerging alien species results from increased accessibility of new source pools. Proceedings of the National Academy of Sciences USA 115: E2264-E2273.

Sharp, R. L., L. R. Larson \& G. T. Green, 2011. Factors influencing public preferences for invasive alien species management. Biological Conservation 144: 2097-2104.

Silva, I., D. Naya, F. Texeira de Mello, A. D’Anatro, G. Tesitore, C. Clavijo \& I. González-Bergonzoni, 2021. Fish vs. Aliens: predatory fish regulate populations of Limnoperna fortunei mitigating impacts on native macroinvertebrate communities. Hydrobiologia. https://doi.org/10.1007/ s10750-020-04421-9.

Simberloff, D., 2021. Maintenance management and eradication of established aquatic invaders. Hydrobiologia. https://doi. org/10.1007/s10750-020-04352-5.

Soriano-Redondo, A., S. Bearhop, L. Lock, S. C. Votier \& G. M. Hilton, 2017. Internet-based monitoring of public perception of conservation. Biological Conservation 206: 304-309.

Stasolla, G., E. Tricarico \& L. Vilizzi, 2021. Risk screening of the potential invasiveness of non-native marine crustacean decapods and barnacles in the Mediterranean Sea. Hydrobiologia. https://doi.org/10.1007/s10750-020-04432-6.

Tavares, M. R., A. C. S. Franco, C. R. R. Ventura \& L. N. Santos, 2021. Geographic distribution of Ophiothela brittle stars (Echinodermata: Ophiuroidea): substrate use plasticity and implications for the silent invasion of $O$. mirabilis in the Atlantic. Hydrobiologia. https://doi.org/10. 1007/s10750-020-04505-6.

Thiébaut, G., M. Tarayre, O. Jambon, N. Le Bris, H. Colinet \& D. Renault, 2021. Variation of thermal plasticity for functional traits between populations of an invasive aquatic plant from two climatic regions. Hydrobiologia. https://doi. org/10.1007/s10750-020-04452-2.

Thomaz, S. M., K. E. Kovalenko, J. E. Havel \& L. B. Kats, 2015. Aquatic invasive species: general trends in the literature and introduction to the special issue. Hydrobiologia 746: $1-12$.

Thomsen, M. S., 2020. Indiscriminate data aggregation in ecological meta-analysis underestimates impacts of invasive species. Nature Ecology and Evolution 4: 312-314.

Troumbis, A. Y., 2017. Declining Google Trends of public interest in biodiversity: semantics, statistics or traceability 
of changing priorities? Biodiversity and Conservation 26: 3421-3443.

Troumbis, A. Y. \& S. Iosifidis, 2020. A decade of Google Trends-based Conservation culturomics research: a critical evaluation of an evolving epistemology. Biological Conservation 248: 108647.

Tyner, E. H. \& T. A. Boyer, 2020. Applying best-worst scaling to rank ecosystem and economic benefits of restoration and conservation in the Great Lakes. Journal of Environmental Management 255: 109888.

Van Riper, C. J., M. H. E. M. Browning, D. Becker, W. Stewart, C. D. Suski, L. Browning \& E. Golebie, 2019. Humannature relationships and normative beliefs influence behaviors that reduce the spread of aquatic invasive species. Environmental Management 63: 69-79.

Verbrugge, L. N. H., R. J. G. Van den Born \& H. J. R. Lenders, 2013. Exploring public perception of non-native species from a visions of nature perspective. Environmental Management 52: 1562-1573.

Verhaegen, G., K. von Jungmeister \& M. Haase, 2021. Life history variation in space and time: environmental and seasonal responses of a parthenogenetic invasive freshwater snail in northern Germany. Hydrobiologia. https:// doi.org/10.1007/s10750-020-04333-.

Zhang, X., D. Ma, M. M. Pulzatto, H. Yu, C. Liu \& D. Yu, 2021. Moderate hydrological disturbance and high nutrient substrate enhance the performance of Myriophyllum aquaticum. Hydrobiologia. https://doi.org/10.1007/s10750020-04397-6.

Publisher's Note Springer Nature remains neutral with regard to jurisdictional claims in published maps and institutional affiliations. 